\title{
Indice general de autores de los números 1-44 (1967-1978)
}

Aberastur, Marcelo. Asia Oriental y Meridional y el Pacífico: inicios de 1972. Año V, No 17 (enero-marzo, 1972).

Acost A, Mercedes y Vilas, Carlos María. Santo Domingo y Checoslovaquia en la política de bloques. Año II, $\mathrm{N}^{\circ} 8$ (eneromarzo, 1969).

AfTaltoN, Marcelo E. La política exterior norteamericana y América Latina. Año $x, N^{0} 37$ (enero-marzo, 1977).

ALMEYDA, Clodomiro. Las OLAS y las crisis política de América Latina. Año I, No 3-4 (octubre, 1967; marzo, 1968).

ANDrade, Gustavo. ¿Hacia dónde va e! Japón? $N^{\circ} 43$ (julio-septiembre 1978).

araujo Castro, josé A. de. El continente americano dentro de la problemática mundial. Año v, $\mathrm{N}^{\circ} 20$ (octubre-diciembre, 1972).

Azız, Sartaj. Los verdaderos problemas de la crisis de alimentos. Año vIII, $\mathrm{N}^{\circ} 30$ (abrit-junio, 1975).

Baltra, Alberto. América Latina y la Segunda UNGTAD. Año :t, $N^{a} 8$ (eneromarzo, 1969).

Ball, W. MacMahon. Australia en el Pacífico. Ario $\mathrm{v}, \mathrm{N}^{\circ} 20$ (octubrc-diciembre, 1972).

BAmbirra, Vania. La revolución cultural y e] marxismo. Año II, $\mathrm{N}^{\circ} 7$ (octubrediciembre, 1968).

Bergsten, C. Fred. Relaciones económicas entre Estados Unidos y Latinoamérica: la estructura internacional y algunos enfoques posibles. Año vin, $\mathrm{N}^{\circ} 31$ (julio-septiembre, 1975).

BERnStein, Enrique. Situación política en víspera de mayo de 1968. Año v, $N^{\circ} 19$ (julio-septiembre, 1972).

Bodenheimer, Susanne. La crisis del movimiento socialdemócrata en América Latina. Asio IV, $\mathrm{N}^{\circ} 12$ (enero-marzo, 1970).

BOGNAR, Jozsef. Reforma económica en Hungria. Año m, $N^{\circ} 10$ (julio-septiembre, 1969).

BuL, Hedley. Las relaciones internacionales como ocupación académica. Año Vir, $\mathrm{N}^{\circ} 28$ (octubrc-diciembre, 1974).
Burton, J.W. No-alineación y politica mundial contemporánea. Ario $\mathrm{m}, \mathrm{N}^{\mathrm{\alpha}}$ ? (abril-junio, 1969).

By'rH, James. Niugini: una nueva nación cuprífera en el Pacífico se acerca a su independencia. Año vI, $\mathrm{N}^{\circ} 22$ (abriljunio, 1973).

CAdena, Cecilia y Joxe, Alain. Armamentismo dependiente: Caso latinoamericano. Año IV, $\mathrm{N}^{0} 14$ (julio-septiembre, 1970).

Cerped, Fernando. La influencia de los organismos internacionales en el proceso colombiano. $\mathrm{N}^{\circ} 43$ (julio-septiembre, 1978).

Ciria, Alberto. La comunicación política en América Latina: Algunos de sus problemas. Año II, $\mathrm{N}^{\circ} 8$ (enero-marzo, 1969).

Clarkson, Stephen. La intelligentsia satélite: Los intelectuales canadienses frente a los Estados Unidos. Año $\mathrm{v}, \mathrm{N}^{\circ} 18$ (abril-junio, 1972).

Claverie Rodriguez, Eliodoro L., Echeverría, Pedro Luis y Villadiba Vera, Jovito A. El tratado modificado de rec:procidad comercial entre Venezuela $y$ los Estados Unidos. Año v, $N^{\circ} 19$ (julioseptiembre, 1972).

ConTANTINEscu, LEONTIN. Las relaciones Estados Unidos-Comunidad Económica Europea en la perspectiva de la Rueda Nixon. Año vi, $\mathrm{N}^{\circ} 21$ (encro-marzo, 1973).

Cotter, Julio. Crisis política y Populismo Militar en el Perú. $N^{\circ} 12$ (encro-marzo, 1970). Año IV.

Croner, Claos. Estudios sobre el subdesarrullo colombiano. Comentario critico. Año IV, $\mathrm{N}^{\circ} 14$ (julio-septiembre, 1970).

Dinmand, Marcelo. Las posibilidades de una técrica nacional en Latinoamérica (el caso argentino). Año :x, $\mathrm{N}^{\circ} 34$ (abriljunio, 1976).

Hacia el cambio del paradigma económico a través de la experiencia de los paises en desarrollo. Año $\mathrm{x}, \mathrm{N}^{\circ} 39$ (julio- septiembre, 1977). 
Diaz A., Rodrigo. La definición internacional de la agresión. $N^{\circ} 43$ (julio-septiembre, 1978).

Dez.gado, Carlos. Sobre algunos problemas de la participación en la Revolución Peruana. Año $\mathrm{v}, \mathrm{N}^{\circ} 21$ (enero-marzo, 1973).

Devillers, Philippe. Francia y la Segunda Guerra del Vietnam. Año II, $N^{0} 6$ (julioseptiembre, 1968).

Diaz Alejandro, Carlos F. E! grupo Andino en el proceso de Integración Latinoamericana. An̄o H, $N^{\circ} 6$ (julio-septiembre, 1968).

Relaciones Norte-Sur: El componente económico. Año $\mathrm{x}, \mathrm{N}^{\circ} 37$ (enero-marzo, 1977).

Egheverria, Pedro Luis, Claverie RodriGuez, Heliodoro L., y Villalba Vera, Jovito A. El tratado modificado de reciprocidad comercial entre Venezuela y los Estados Unidos, Año v, $N^{\circ} 19$ (julioseptiembre, 1972).

ENND, HEINRICH, La política exterior del gobierno Kissinger-Brandt. Año II, $\mathrm{N}^{\mathrm{o}} 7$ (octubre-diciembre, 1968).

FAGEN, Richard. La politica exterior de los Estados Unidos y el desarrollo del Tercer Mundo. Año Ix, $\mathrm{N}^{\circ} 35$ (julio-septiembre, 1976).

FAÚNDEZ, Julio. E! Sistema Interamericano de Seguridad en la política exterior de Estados Unidos. Año Ill, $\mathrm{N}^{\circ} 11$ (octubrediciembre, 1969).

El presidente de Estados Unidos y la facultad para hacer la guerra. Año Iv, $N^{\circ} 15$ (octubre-diciembre, 1970).

Ferrer, Aldo. Relaciones económicas entre la Comunidad Económica Europea y América Latina. Año vi, $N^{\circ} 24$ (octubrediciembre, 1973).

Lá crisis del sistema monetario Internacional. Un enfoque estructuralista. Año viII, $N^{\circ} 30$ (abril-junio, 1975).

La crisis del sistema Trilateral y América Latina. $N^{\circ} 42$ (abril-junio, 1978).

Flores de LA PENA, Horacio. Un nuevo modelo de desarrollo. Año $\mathrm{X}, \mathrm{N}^{0} 39$ (julio-septiembre, 1977).

Frenech Davis, Ricardo. Pacto andino $y$ libre comercio. Año $\mathrm{X}, \mathrm{N}^{\circ} 38$ (abriljunio, 1977).

Frondizzi, Arturo. El problema nacional de América Latina y ciertos esquemas de integración regional. $N^{\text {to* }} 3$ y 4 (octubre, 1967-marzo, 1968). Año I.

FoGARTY, John. Australia y el probiema de las inversiones extranjeras. Año , VI, $\mathrm{N}^{\circ} 22$ (abril-junio, 1973).

Fuenzalida, Edmundo y SUNKel, Osvaldo. Capitalismo transnacional y desarrollo nacional, $\mathrm{N}^{\mathrm{o}} 44$. (octubre-diciembre, 1978).

Furtado, Celso. La concentración del poder económico en los Estados Unidos y sus proyecciones en América Latina. Nos 3 y 4 (octubre, 1967-marzo, 1968). Año I.

El conocimiento económico de América Latina. Ario $1 \mathrm{x}, \mathrm{N}^{\circ} 36$ (septiembre-diciembre, 1976).

Proceso y frustración de las reformas agrarias en América Latina. $\mathrm{N}^{\text {os }} 3$ y 4 (octubre, 1967-marzo, 1968). Año 1.

Una interpretación estructuralista de la "crisis" actual del capitalismo. Año viI, $\mathrm{N}^{\circ} 30$ (abril-junio, 1975).

Girvan, Norman. El conflicto de GuyanaALCAN y la nacionalización de DEMBA. Año v, No 19 (julio-septiembre, 1972).

Teorías de dependencia económica en el Caribe y Latinoamérica: un estudio comparativo. Año vi, $\mathrm{N}^{\circ} 23$ (julio-septiembre, 1973).

Gittings, John. ¿Tiene China una politica exterior? $N^{\circ} 1$ (abril, 1967), Año I.

Libros sobre la guerra en Vietnam, $\mathrm{N}^{\circ} 2$ (julio, 1967). Año I.

El ejército Popular de Liberación y la Revolución Cultural. Año $11, \mathrm{~N}^{\circ} 5$ (abril-junio, 1968).

La nueva guerra en Indochina. Año $\mathrm{rv}$, $\mathrm{N}^{\circ} 14$ (julio-septicmbre, 1970).

Godoy, Horacio H. La integración de América Latina y el proceso del poder mundial. Año II, $\mathrm{N}^{\circ} 7$ (octubre-diciembre, 1968).

Los acuerdos entre los Estados Unidos y la Unión de las Repúblicas Socialistas Soviéticas. Año vII, No 28 (octubre-diciembre, 1974).

Godfrey, Martin y LANG, Don Steven. ¿Socios en el subdesarrollo? El proceso de transnacionalización en el contexto de Kenya. $\mathrm{N}^{\circ} 44$ (octubre-diciembre, 1978).

Gort, Richard. El sur de Africa y el fin de la guerra fría. $N^{\circ} 1$ (abril, 1967). Año I. 
El Congo a partir de Mobutu. Nos $3 y$ 4 (octubre, 1967-marzo, 1968). Año t.

La experiencia guerrillera en Bolivia. Año I1, $N^{0} .5$ (abril-junio, 1968).

Grant, Bruce. Australia y el Pacífico. Año v, $N^{\circ} 17$ (en ero-marzo, 1972).

Grant, James P. Las naciones de la opep: ¿Asociados o competidores? Año vili, No 30 (abril-junio, 1975).

Grayson, George W. Jr. Portugal y el Movimiento de las Fuerzas Armadas. Año Ix, $\mathrm{N}^{\circ} 33$ (enero-marzo, 1976).

Griffith Jones, Stephany. El crecimiento de la Banca Multinacional. $N^{\circ} 44$ (octubre-diciembre, 1976).

Guerrero, Mauricio y Sagasti, Francisco. Situación de la Ciencia y Tecnología en América Latina. Año VIr, $\mathrm{N}^{\circ} 25$ (eneromarzo, 1974).

Halty Carrere, Máximo. ¿ Hacia un nuevo orden tecnológico. Año vili. $N^{0} 32$ (octubre-diciembre, 1975).

Hansen, Roger. Relaciones económicas entre los Estados Unidos y América Latina. ¿Bilaterales, regionales o globales? Año vIr, $N^{\circ} 31$ (julio-septiembre, 1975).

Ut HaQ, Mahbud. El Diálogo Norte-Sur: la segunda fase. $N^{\circ} 41$ (enero-marzo, 1978).

Herrera, Amílcar O. La ciencia en el desarollo de América Latina. Año II, $\mathrm{N}^{\circ} 5$ (abril-junio, 1968).

Herrera, Felipe. Viabilidad de una comunidad latinoamericana. Ar̃o $1, N^{a} 1$ (abril, 1967).

La tarea inconclusa: América Latina integrada. Año vi, $\mathrm{N}^{\circ} 21$ (enero-marzo, 1973).

América Latina y el desafio internacional para la educación. Año viI, $\mathrm{N}^{\circ} 25$ (enero-marzo, 1974).

América Latina y el Tercer Mundo. Año $\mathrm{x}, \mathrm{N}^{\circ} 40$ (octubre-diciembre, 1977).

Las políticas culturales de América Latina. $N^{\circ} 43$ (julio-septiembre, 1978).

Hirschman, Albert $O$. Liderazgo, percepción del cambio y subdesarrollo. Año II, $\mathrm{N}^{\circ} 6$ (julio-septiembre, 1968).

Hodara, Joseph. La estructura internacional: cuatro versiones. Año vili, $N^{\circ} 31$ (julio-septiembre, 1975).

Hoffman, Stanley. El estilo norteamericano: su pasado, sus principios. Año :II, $N^{2} 9$ (abril-junio, 1969).

Holmanad, Carsten. El papel de las poten- cias medias en la política internacional. Año $v, N^{\circ} 17$ (enero-marzo, 1972).

Hurtado, Héctor, Pazos, Javier y MayoBRE, Eduardo. El Caribe y Venezuela: integración de la. integración. Año vir, $N^{\circ} 27$ (julio-septiembre, 1974).

Iglesias, Enrique V. Transferencia de recursos en el ámbito internacional. Año ix, $\mathrm{N}^{\circ} 34$ (abril-junio, 1976).

Situación y perspectivas de América Latina. Año $\mathrm{x}, \mathrm{N}^{\circ} 39$ (julio-septiembre, 1977).

¿Va América Latina hacia la Bancarrota? $N^{\circ} 42$ (abril-junio, 1978).

Imaz, José Luis de. ¿Adiós a la teoría de la dependencia? Una perspectiva desde la Argentina. Año vil, $\mathrm{N}^{\circ} 28$ (octubre-diciembre, 1974).

IreLAND, Rowan. La Iglesia Católica del Brasil: límites del aggiornamiento. Año vi, $N^{\circ} .27$ (julio-septiembre, 1974).

Jacuaribe, Helio. El equilibrio ecológico mundial y los países subdesarroliados. Anov, $\mathrm{N}^{\circ} 17$ (enero-marzo, 1972).

L.os acontecimientos chilenos. Año VII, $N^{\circ}$ 26.(abril-junio, 1974).

Brasil y la América Latina. Año VIII, $N^{\circ} 29$ (enero-marzo, 1975).

El Vietnam y los Estados Unidos. Año viI, $N^{\circ} 31$ (julio-septiembre, 1975).

El estudio del futuro y de la supervivencia del hombre, Año Ix, $\mathrm{N}^{\circ} 36$ (septiembre-diciembre, 1976).

El informe Linowitz $y$ las relaciones Estados Unidos-América. Año $\mathrm{X}, \mathrm{N}^{\circ} 40$ (octubre-diciembre, 1977).

Joxe, Alain. Hacia una nueva concepción de la seguridad curopea. Año $\mathrm{I}, \mathrm{N}^{\circ} 2$ (julio, 1967).

Cohetes anticohetes: ¿Regreso a estrategias defensivas? Año II, $N^{\circ} 5$ (abriljunio 1968).

Doctrina estratégica y guerras de intervención. Año It, $N^{\circ} 6$ (julio-septiembre, 1968).

$¿$ Fin de la preponderancia estratégica norteamericana? Año II, $N^{\circ} 11$ (octubrediciembre, 1968).

Joxe, Alain y Cadena, Cecilia. Armamentismo dependiente: Caso latinoamericano. Año $\mathrm{IV}, \mathrm{N}^{\circ} 14$ (julio-septiembre, 1970);

KADAR, Bela. Los países pequeños en la economia mundial. Año IV, $\mathrm{N}^{\circ} 16$ (enteromarzo, 1971). 
KAISER, Kari. Una nueva política oriental en Alemania. Año II, $N^{\circ} 8$ (enero-marzo, 1969).

KaLECK, M. y KULA, Marcin. Notas sobre los aspectos sociales y económicos de los "Regímenes Intermedios", el caso de Bolivia. Año $\mathrm{rv}, \mathrm{N}^{\circ} 15$ (octubre-diciembre, 1970).

Kojma, Kiyoshi. Un área de libre comercio del Pacífico. Año v, $\mathrm{N}^{\circ} 20$ (octubrediciembre, 1972).

Kula, Marcin y Kalecki, M. Notas sobre los aspectos sociales y económicos de los "Regimenes Intermedios"; el caso de Bolivia. Año IV, $\mathrm{N}^{\circ} 1.5$ (octubre-diciembre, 1970).

LAFER, Celso. Una redefinición del orden mundial y la Alianza Latinoamericana. Perspectivas y posibilidades. Año vIII, $N^{\circ} 31$ (julio-septiembre, 1975).

El estudio de las Relaciones Internaciunales de América Latina. $\mathrm{N}^{\circ} 43$ (julioseptiembre, 1978).

Lacos, Gustavo. El plan Carter y "La Guerra de la Energia". Año x, $\mathrm{N}^{\circ} 40$ (octubre-diciembre, 1977).

Lanedon, Steven y Godfrey, Martin. ¿Socios en el subdesarrollo? El proceso de transnacionalización en el contacto de Kenya. $N^{\circ} 44$ (octubre-diciembre, 1978).

Langlors, Juan Carlos. Una nueva dimensión para los Bancos de Desarrollo. Año Ix, No 33 (enero-marzo, 1976).

LOWENTHAL, Richard. Alemania y el fin del sistema bipolar en la politica internacional. Año $: \mathrm{N}^{a *} 3$ y 4 (octubre, 1967-marzo, 1968).

Ejércitos y politica en América Latina. Año 1X, $N^{\circ} 35$ (julio-septiembre, 1976).

El fin de la presunción hegemónica. Año $X, N^{\circ} 37$ (enero-marzo, 1977).

LUNA, Julio. El desarrollo pesquero y la integración regional. Año $\mathrm{IV}, \mathrm{N}^{\mathrm{o}} 14$ (julio-septiembre, 1970).

Martins, Luciano. Mayo de 1968: una revolución nueva e intransitiva. Año $\mathrm{II}$, $\mathrm{N}^{\circ} 10$ (julio-septiembre, 1969).

Mattelart, Armand. La dependencia de los medios de comunicación de masas en Chile. Año rv, No 13 (abril-junio, 1970).

Mayobre, Eduardo, Hurtado, Héctor $y$ Pazos, Javier. El Caribe y Venezuela: integración de la integración. Año vil, $\mathrm{N}^{\circ} 27$ (julio-septiembre, 1974).

MerLiNI, Cesare. La posición internacional de Italia. Oportunidades y tentaciones. Año $V, N^{\circ} 17$ (enero-marzo, 1972).

Mihaly, Eugene B. La estrategia de los Estados Unidos en el Pacífico Occidental y el dilema de Micronesia. Año $\mathrm{v}, \mathrm{N}^{\circ} 17$ (enero-marzo, 1972).

Millar, T.B. Los Océanos Indico y Pacífico: Algunas consideraciones estratégicas. Año :11, $N^{\circ} 11$ (octubre-diciembre, 1969).

MIRSKI, Gueorgui. El papel político del ejército en los paises de Asia y Africa. Año lv, $N^{\circ} 13$ (abril-junio, 1970).

Moneta, Juan Carlos. Argentina y Australia: Esquemas para la cooperación. Año vi, $\mathrm{N}^{\circ} 21$ (enero-marzo, 1973).

Africa $y$ los grandes actores externos. Año vil, $\mathrm{N}^{\circ} 27$ (julio-septiembre, 1974).

Moran, Theodore H. Nuevo trato a las materias primas. Año $\mathrm{v}, \mathrm{N}^{\circ} 19$ Gulioseptiembre, 1972).

MUNOZ, Heraldo y SANCHEZ, Walter. La Détente y el Sistema Internacional. Año vilt, $\mathrm{N}^{\circ} 32$ (octubre-diciembre, 1975).

MUNoz, Heraldo. Dependencia estratégica y no-estratégica: materias primas y relaciones en la perspectiva de la crisis petrolera, Año Ix, $\mathrm{N}^{\circ} 33$ (enero-marzo, 1976).

Cambio y continuidad en el debate sobre la dependencia. $\mathrm{N}^{\circ} 44$ (octubre-diciembre, 1978).

Murphy, Cornelius F. Jr. Coacción económica $y$ tratados desiguales. Año $\mathrm{IV}, \mathrm{N}^{\circ} 14$ (julio-septiembre, 1970).

Naudon, Carlos. Cinco libros sobre Israel. Año Il, $\mathrm{N}^{\circ} 6$ (julio-septiembre, 1968).

Niekerk, Arnold Van. La pendiente de la dependencia: una versión desde afuera. Ario $v, N^{\circ} 18$ (abril-junio, 1972).

América Latina y las Antillas Neerlandesas. Año VI, $\mathrm{N}^{\circ} 23$ (julio-septiembre, 1973).

La sociologia latinoamericana: un testimonio epistemológico. Año $\mathrm{IX}, \mathrm{N}^{\mathrm{o}} 36$ (septiembre-diciembre, 1976).

OGersby, J.C.M. Relaciones canadienselatinoamericanas, pasadas, presentes y futuras. Año v, $N^{\circ} 18$ (abril-junio, 1972).

OLDFELT, Carin. Estudio comparativo sobre zonas pesqueras en el mundo. Año $n$, $N^{\circ} 13$ (abril-junio, 1970).

Orreco Vicuna, Francisco. Dilema en el Grupo Andino. Año III, $N^{\circ}$ it (octubrediciembre, 1969).

Algunos problemas de derecho interna- 
cional planteados por la nacionalización de la industria del cobre en Chile. Año vI, $N^{\circ} 24$ (octubre-diciembre, 1973).

De la crisis de la energía al concepto del patrimonio económico de la humanidad: criterios para restructurar el sistema económico internacional. Ar̃o vill, $\mathrm{N}^{\circ} 32$ (octubre-diciembre, 1975).

Las alternativas de América Latina como clase media de las naciones. Año $\mathrm{x}, \mathrm{N}^{\circ}$ 40 (octubre-diciembre, 1977).

ORTIz, Eduardo. Las grandes potencias y la crisis de Nigeria. Año $111, \mathrm{~N}^{\circ} 9$ (abriljunio, 1969).

Palma, Pedro A. Análisis 'del Sistema Monetario Internacional. An̄o viu, $\mathrm{N}^{\circ} 32$ (octubre-diciembre, 1975).

Palma Vicuna, Ignacio. Aportes para un análisis de la crisis chilena. Año vu, $N^{a} 26$ (abril-junio, 1974).

Pazos, Javier, Hurtado, Héctor y MayoBRE, Eduardo, El Caribe y Venezuela: integración de la integración. Año vit, $N^{\circ} 27$ (julio-septiembre, 1974).

PENa, Félix. El Grupo Andino: un nuevo enfoque de la participación internacional de los paises en desarrollo. Año vi, $\mathrm{N}^{\circ} 22$ (abril-junio, 1973).

Tendencias y perspectivas de la integración económica en América Latina. Año VIII, $N^{\circ} 29$ (encro-marzo, 1975).

Perez Llana, Carlos E. América Latina y los países no alineados. Año vi, $\mathrm{N}^{\circ} 24$ (octubre-diciembre, 1973).

¿Potencias intermedias o paises mayores? La política exterior de Argentina, Brasil y México. Año viri, N²9 (enero-marzo, 1975).

El legado de Henry Kissinger: algunas implicancias. Año $\mathrm{X}, \mathrm{N}^{0} 37$ (enero-marzo, 1977).

PerRY, Guillermo. Los mercados mundiales de manufacturas y la industrialización de los países en desarrollo. $\mathrm{N}^{\circ} 42$ (abritjunio, 1978).

Petras, James y Rimernsnyder, Nelson. Los militares y la modernización del Perú, Año Iv, $\mathrm{N}^{\circ} 13$ (abril-junio, 1970).

Petras, James. Verezuela: una década de democracia capitalista. Año IV, . $\mathrm{N}^{\circ} 1.5$ (octubre-diciembre, 1970).

Pinto, Aríbal. Relaciones cconómicas entre América Latina y Estados Unidos: Implicaciones y perspectivas políticas. Año $\mathrm{Vi}, \mathrm{N}^{\circ} 22$ (abril-junio, 1973).
Prebisch, Raúl. El nuevo orden económico internacional, contradicciones del sistema centroperiferia, $\mathrm{N}^{\circ} 43$ (julio-septiembre, 1978).

Ribeiko, Darcy. El desafío de la marginalidad. Año Iv, $\mathrm{N}^{\circ} 16$ (enero-marzo, 1971). Nuevos caminos de la Revolución Latinoamericana, Año v, $\mathrm{N}^{\circ} 18$ (abril-junio, 1972).

Sabato, Jorge A. Energía Atómica en Argentina. Año n, $\mathrm{N}^{\circ} 7$ (octubre-diciembre, 1968).

El cambio tecnológico necesario y posible. Año IX, $\mathrm{N}^{\circ} 36$ (septiembre-diciembre, 1976).

El plan nuclear brasilero y ta bomba atómica. $N^{\circ} 41$ (cnero-mar̨zo, 1978).

SACHs, Ignacy. Ecodesarrollo: un aporte a la definición de estilos de desarrollo para América Latina. Año VIr, $N^{\circ} 25$ (eneromarzo, 1974).

Sagasti, Francisco y Guerrero, Mauricio. Ssituación de la ciencia y tecnología en América Latina. Año vII, $\mathrm{N}^{\circ} 25$ (eneromarzo, 1974).

Sagasti, Francisco R. Audodependencia tecnológica y cooperación entre los países del Tercer Mundo. Año $\mathrm{IX}, \mathrm{N}^{\circ} 33$ (enero-marzo, 1976).

Salgado, Germánico. Integración, conciliación de políticas y diferencias de estructura económica. Año $\mathrm{x}, \mathrm{N}^{\circ} 38$ (abriljunio, 1977).

Sampaio Malan, Pedro. Las relaciones económicas internacionales de Brasil: notas para una agenda de investigación. $\mathrm{N}^{\circ} 41$ (enero-marzo, 1978).

SANGHEZ, Walter y MUNoz, Heralds. La Détente y el Sistema Internacional. Año vIII, $N^{\circ} 32$ (octubre-diciembre, 1975).

SANGhez, Walter. El Triángulo WashingtonMoscú - Pekin y el proceso de distensión internaciona!. Año 1X, $\mathrm{N}^{\circ} 35$ (julioseptiembre, 1976).

Sathyamurthy, T.V. Las relaciones internacionales asiáticas: perspectivas contemporáneas. Año $\mathrm{N}, \mathrm{N}^{\circ} 1.5$ (octubrediciembre, 1970).

SChmrrter, Philippe C. La portugalización de Brasil. Año v, $\mathrm{N}^{\circ} 19$ (julio-septiembre, 1972). 
SePUllveda, Alberto. El militarismo desarroilista en América Latina. Año $N, N^{\circ} 15$ (octubre-diciembre, 1970).

SEWELL, John. El crecimiento del Norte. ¿Es posible sin el progreso del Sur? $\mathrm{N}^{\circ}$ 42 (abril-junio, 1978).

Sigmund, Paul E. El bloqueo invisible y la caida de Allende. Año viI, $\mathrm{N}^{\circ} 26$ (abriljunio, 1974).

Silva Castro, Raúl. Juan Egaña, precursor de la integración latinoamericana. Año II, $\mathrm{N}^{\circ} 7$ (octubre-diciembre, 1968).

Silva Michelena, José A. Tendencias recientes en la política mundial. Año vi, $N^{\circ} 23$ (julio-septiembre), 1973).

SNow, Peter G. Desarrollo económico y Seguridad Nacional en el Régimen Militar Argentino. Año v, $\mathrm{N}^{\circ} 20$ (octubrediciembre, 1972).

Sunkel, Osvaldo. Política nacional de desarrollo y dependencia externa. Año $\mathrm{I}$, $N^{\circ} 1$ (abril, 1967).

La tarea política y tcórica del planificador en América Latina. Año $\mathrm{n}, \mathrm{N}^{\circ} 8$ (enero-marzo, 1969).

Esperando a Godot: América Latina ante la nueva administración republicana de los Estados Unidos. Año III, $\mathrm{N}^{\circ} 9$ (abriljunio, 1969).

La Universidad Latinoamericana ante e! avance científico y técnico; algunas reflexiones. Año IV, $\mathrm{N}^{\circ} 13$ (abril-junio, 1970).

Capitalismo transnacional y desintegración nacional en América Latina. Año Iv, $\mathrm{N}^{\circ} 16$ (enero-marzo, 1971).

El desarroilo de la teoria del desarrollo. Año $X, N^{\circ} 40$ (octubre-diciembre, 1977).

Sunkel, Osvaldo y Fuenzalida, Edmundo. Capitalismo transnacional $y$ desarrollo nacional. $\mathrm{N}^{\circ} 44$ (octubre-diciembre, 1978).

TADIC, Bojana. No-alineación: un vistazo histórico y conceptual. Año III, $N^{\circ} 10$ (julio-septiembre, 1969).

Tetrelbom, Sergio, Los países del Pacifico Sur y el mar territorial. Año $\mathrm{N}, \mathrm{N}^{\circ} 13$ (abril-junio, 1970).

Thomas, Hugh, La Revolución Cubana $y$ sus raíces históricas. Año $\mathrm{rv}, \mathrm{N}^{\circ} 16$ (enero-marzo, 1971).

Thomson, James C. Jr. Vietnam: un caso clínico. Año II, $\mathrm{N}^{\circ} 7$ (octubre-diciembre, 1968).
TiRoni, Ernesto. Las estrategias nacionales de desarrollo y la integración de los Paises Andinos. Año Ix, $\mathrm{N}^{\circ} 34$ (abril-junio, 1976).

La Decisión 24 sobre capitales extranjeros en el Grupo Andino, Año $x, N^{\circ} 38$ (abril-junio, 1977).

Tomassini, Luciano. La misión imposible del presidente Nixon: Año IV, $\mathrm{N}^{\circ} 12$ (eneromarzo, 1970).

Implicaciones internacionales del deterioro ecológico. Año $\mathrm{v}, \mathrm{N}^{\circ} 18$ (abriljunio, 1972).

Tendencias favorabics o adversas a la formación de un sistema regional latinoamericano. Año vill, $\mathrm{N}^{\circ} 29$ (enero-marzo, 1975).

Falencias y falacias: notas sobre el estudio de las relaciones Norte-Sur. Año $x$, $N^{\circ} 40$ (octubre-diciembre, 1977).

Intereses mutuos: las verdaderas bases de! diálogo Norte-Sur. $N^{\circ} 41$ (eneromarzo, 1978).

Torres-Rivas, Edelberto. Desarrollo, integración $y$ dependencia en Centroamérica. Año rv, No 12 (enero-marzo, 1970).

ToYNBEe, Arnold. El estudio de la historia contemporánea. Año I, $N^{\circ} 1$ (abril, 1967).

Uslar Pietri, Arturo. Lo específico del hombre latinoamericano. Año IX, $\mathrm{N}^{\circ} 36$ (septiembre-diciembre, 1976).

Valdés Subercaseaux, Gabriel. Situación de! Grupo Andino en el contexto latinoamericano e internacional. Año $\mathrm{x}, \mathrm{N}^{\circ} 38$ (abril-junio, 1977).

Van Dam, André. El triunfo del caballo. Año IX, No 34 (abril-junio, 1976).

Vargas Hidal,go, Rafacl. Estados Unidos y América Latina bajo la presidencia de Carter. $\mathrm{N}^{\circ} 41$ (enero-marzo, 1978).

VELL2, Claudio. EI Instituto de Estudios Internacionales. Año I, $\mathrm{N}^{\circ} 1$ (abril, 1967). Centralismo, Nacionalismo e Integración. Año $11, \mathrm{~N}^{\circ} 9$ (abril-junio, 1969).

Cambio y continuidad: El Pacto Andino cn la historia contemporánea. Año ry, $N^{\circ} 16$ (enero-marzo, 1971).

Errores y omisiones: notas sobre la política exterior de los países de América Latina durante los últimos diez años. Año x, $N^{\circ} 40$ (octubre-diciembre, 1977).

VernaNT, Jacques. El mundo, Europa y Francia. Año I, $N^{\circ} 2$ (julio, 1967).

VILAS, Carlos Maria y Acosta, Mercedes, Santo Domingo y Checoslovaquia en la 
política de bloques. Ario $u, N^{\circ} 8$ (eneromarzo, 1969).

Villalba Vera, Jovito A., Claverie RoDRIGUE2, Heliodoro L. Y ECHEVERRiA, Pedro Luis. El Tratado modificado de reciprocidad comercial entre Venezuela y los Estados Unidos. Año v, N 19 (julio-septiembre, 1972).

VILLAMIL, Josć. El proceso de transnacionalización en el caso del Caribe. $\mathrm{N}^{\circ} 44$ (octubre-dicicmbre, 1978).

VILLAGrAN KRAMER, Francisco. Mecanismos de regulación internacional de productos básicos. Anjo vi, $\mathrm{N}^{\circ} 23$ (julio-septiembre, 1973).

Wallis, Victor. La experiencia de Brasi! con una política exterior independientc. Año I, No 2 (julio, 1967).
Ward, Bárbara. Perspectivas históricas del nuevo orden económico internacional. $\mathrm{N}^{\circ} 41$ (enero-marzo, 1978).

WaṬkins, Melville $\mathrm{H}$. Canadá: industria y propiedad extranjera. Año $\mathrm{ml}, \mathrm{N}^{\circ} 10$ (julio-septiembre, 1969).

WERTHEIM, W.F. Indonesia antes y después del golpe de Untung. Año :, $\mathrm{N}^{\circ} 3$ (octubre, 1967 - marzo, 1968).

WiLhELmY, Manfred. La politica exterior chilena en el Grupo Andino. Año $x$, $N^{\circ} 38$ (abril-junio, 1977).

La política exterior de los Estados Unidos dinámica interna y nuevos problemas. $\mathrm{N}^{\circ} 42$ (abrit-junio, 1978).

Youncer, Kenneth. El papel de Gran Bretaña en la politica internacional. Año I, No2 (julio, 1967). 